UCRL-JC-125835

PREPRINT

\title{
Burstman: A Portable GRB Detector for Really Long Voyages
}

\author{
K. Hurley, J. H. Primbsch, P. Berg, K. Ziock \\ I. Mitrofanov, D. Anfimov, A. Chernenko, V. Dolidze, V. Loznikov, \\ A. Pozanenko, A. Tonshev, D. Ushakov, T. Cline, R. Baker, D. Stilwell, \\ D. Sheppard, N. Madden
}

This paper was prepared for submittal to the 3rd Huntsville Workshop on Gamma-Ray Burst Huntsville, Alabama

October 5-6, 1995

October, 1995

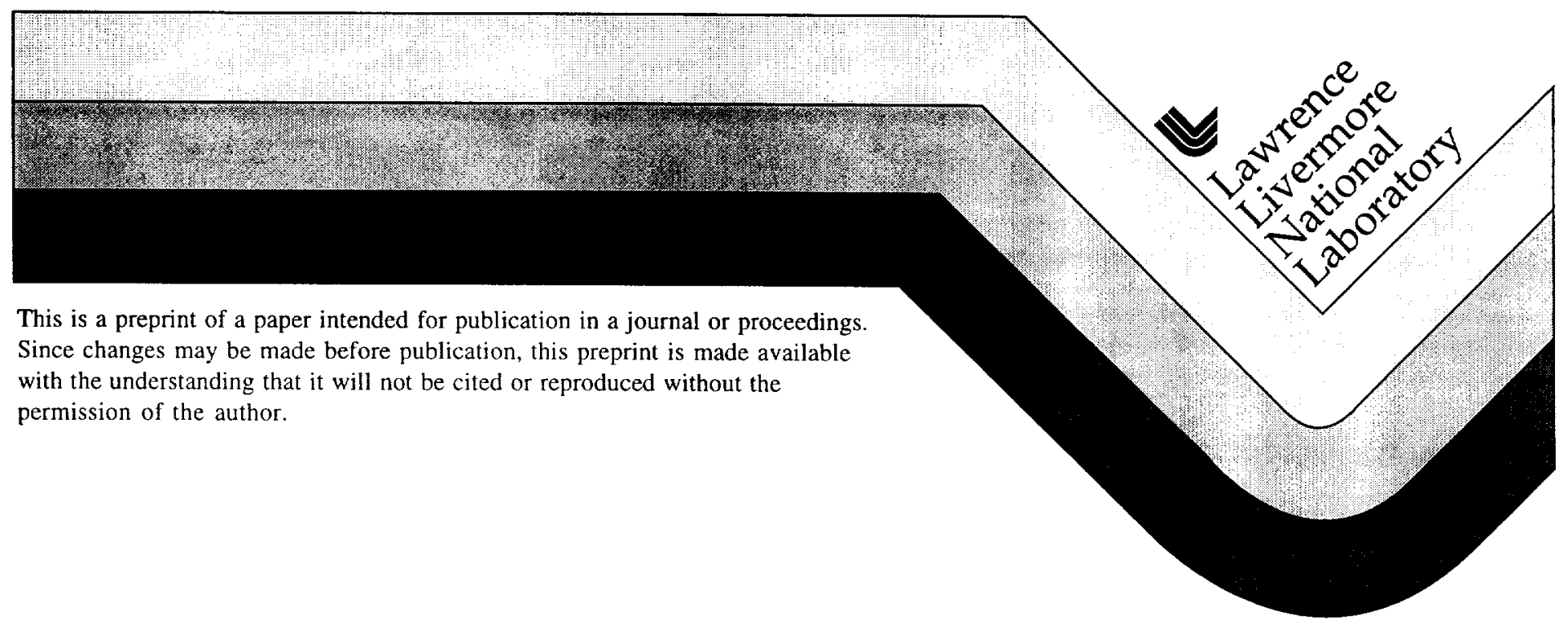




\section{DISCLAIMER}

This document was prepared as an account of work sponsored by an agency of the United States Government. Neither the United States Government nor the University of California nor any of their employees, makes any warranty, express or implied, or assumes any legal liability or responsibility for the accuracy, completeness, or usefulness of any information, apparatus, product, or process

disclosed, or represents that its use would not infringe privately owned rights. Reference herein to any specific commercial product, process, or service by trade name, trademark, manufacturer, or otherwise, does not necessarily constitute or imply its endorsement, recommendation, or favoring by the United States Government or the University of California. The views and opinions of authors expressed herein do not necessarily state or reflect those of the United States Government or the University of California, and shall not be used for advertising or product endorsement purposes. 


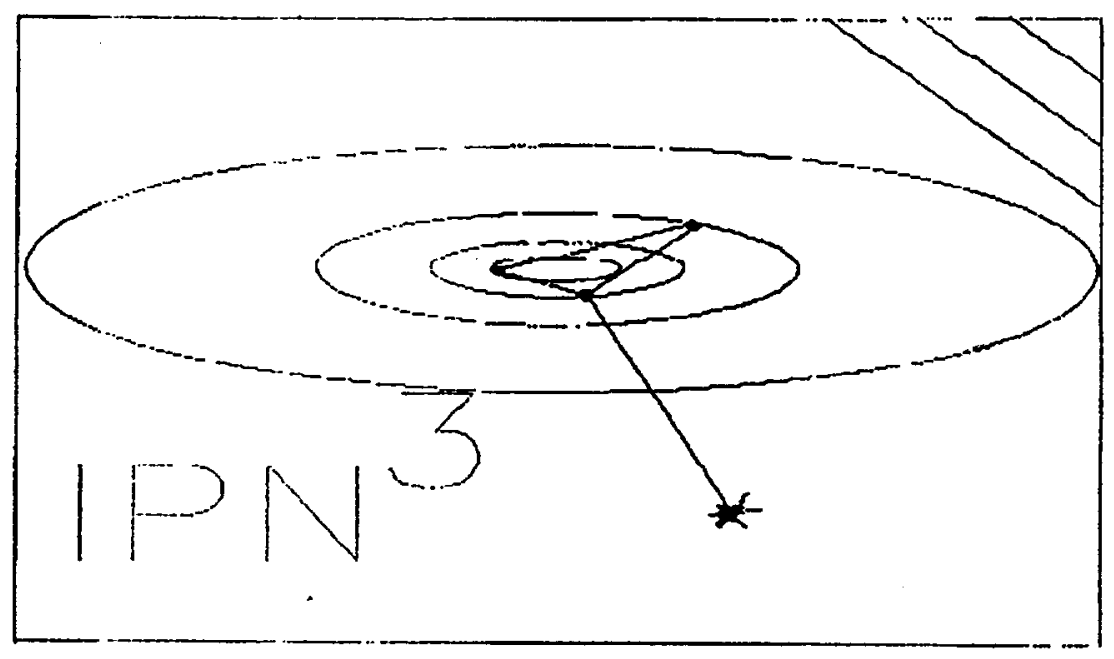

University of California at Berkeley Space Sciences Laboratory

Burstman: A l'ortable GRB Detector for Really Long Voyages

R. Hurley, J.H. Primbsch, P. Berg

U.C. Berkelcy Space Soienoes Laboratory

Berkeley, CA 94720-7450

\section{K. Ziock}

Lawrence Livermore National Laboratory

L-296

Livermore, CA 94550

I. Mitrofanov, D. Anfimov, A. Chemenko, V. Dolidze, V. Loznikov, A. Pozanenko. A. Tonshev, D. Ushakov

Institute for Space Rescarch

Profsoyouznaya 34/32, 117810 Moscow

T. Cline, R. Baker, D. Stilwell, D. Sheppard

NASA Goddard Space Flight Center

Grecubelt, MD 20771

N. Madden

Lawrence Berkeley Laboratory

29-204

Berkeley. CA 94720

Presented at the 3rd Huntsville Workshop on Gamma-Ray Bursts, October 1995 


\begin{abstract}
The renewal of the Ulysses mission to the year 2001, and the failure of Mars Observer, once inore leave the Interplanetary Network with only two widely spaced components. We have thereforo developed and begun to build a small GRB derector for the Russian Mars '96 mission. A prototype has now been delivered to Russia for spacecraft tests. Three interesting features of this oxporimont are first, that it measuros both particles and gamma rays, second, that it is not much larger them a Walkman (hence the name), and third, that it is being constructed with support only from discretionary funds at a number of institutes. We discuss the types of measurements that Burstman will make, as well as the quantity and quality of the small error boxes that will be obtained during the two year (nominal) Mars ' 96 mission.
\end{abstract}

\title{
Introduction
}

The third interplanetary network has boen without a distant third spacceraft since the loss of Mars Observer in 1993. Since the Ulysses mission will operate until 2001, and the Compton Gamma-Ray Observatory will be extended for at least a few more years. we have begun development of a small burst detector which will be proposed for future planetary missions. Its first flight will be on the Russian Mars ' 96 spacecraft, to be launched in November 1996.

The prototype version of this experiment, which we call Burstman, was developed in only a year, using discretionary funding from the California Space Institute, the Institute for Gooptysics and Planetary Physics, Lawrence Livermore National Laboratory. Goddard Space Flight Center, and Lawrence Berkeley Laboratory. To enhance the scientific return from outer planet missions, we have designed it to detect and distinguish both energetic particles, such as electrons and protons, and photons.

\section{Characteristics and Expected Performance}

The essential physical characteristics of the experiment are the following: its dimensions are $150 \times 190 \times 75 \mathrm{~mm}$, its mass is $750 \mathrm{~g}$, and it consumes $550 \mathrm{~mW}$ of power, excluding the heater. It should be possible to reduce the size, and pertaps the mass, of future versions with more development effort. The sensor consists of a CsI/plastic phoswich; each layer is $3 \mathrm{~mm}$ thick, and the surface area is $20 \mathrm{~cm}^{2}$. The overall design is loosely based on that of the Ulysses GRB experiment (Hurley et al. 1992). The sensor is the responsibility of Lawrence Livermore National Laboratory, the analog electronics was designed and built at Lawrence Berkeley Laboratory and the Space Sciences Laboratory, while the digital electronics and ground support equipment were developed and built at Goddard Space Flight Center. The prototype is shown in Figure 1.

The experiment has numerous operating modes and can adapt to various telcmetry ratos siarting around $40 \mathrm{~b} / \mathrm{s}$. Configured for the Mars ' 96 mission, it returns particle rates (but not cnergy spectra) with time resolution $0.25 \mathrm{~s}$, gamma-ray burst rates with high time 


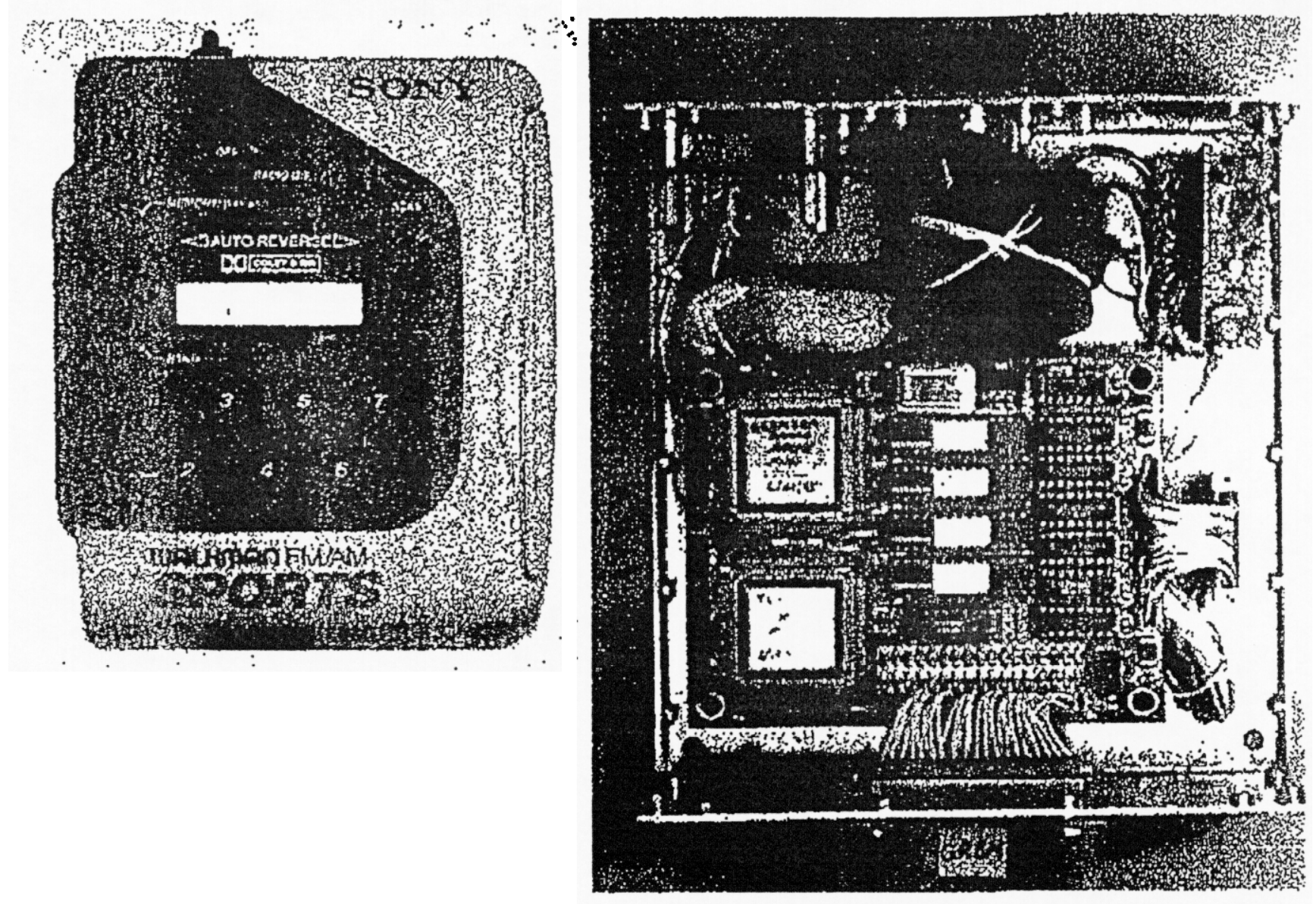

Figure 1. Walkman (left) and Burstman (right).

resolution (typically $8 \mathrm{~ms}$ following a trigger), and energy spectra with coarser resolution. The nominal energy range for photons is $25-150 \mathrm{keV}$. The Mars " 96 version has a single sensor unit (as opposed to two sensor units aboard Ulysses) and thus will cover $2 \pi$ sr with good efficiency, and another $2 \pi 8 \pi$ with reduced efficiency. We anticipate that the trigger threshold for bursts will be $\sim 10^{-6} \mathrm{erg} \mathrm{cm}^{-2}$. Bursts can also be detected in the real-time (untriggered) photon data, with resolution $\sim 0.25 \mathrm{~s}$. Scaling from the Ulysses burst detection rate, we expect to detect approximately 100 cosmic events/year.

\section{Conclusions}

As of this writing. the prototype detector has been integrated aboard the Mars '96 spacecraft. The first flight unit is undergoing qualification testing, and will be delivered to Moscow in November 1995. A second flight unit will then be fabricated.

The nominal Mars ' 96 mission duration is two years. Thus between 1996 and 1998, the 3 rd Interplanetary Network will consist of Uiysses, Mars '96, CGRO, Wind, and other near-Earth missions. At the launch of Mars ' 96 , Ulysses will be 4.8 AU from Earti; its distance will reach 6.2 AUJ withir less than one year. Mars ' 96 will reach distances of 
2.4 AU from Earth. Thus for bright bursts and favorable geometries, many of the two hundred events detected will be localized to arcminute accuracies and better.

\section{Acknowledgments}

This experiment was developed and built with the following support. Institute for Geophysics and Planetary Physics LLL-B291405; California Space Institute CS-23-94; LLNL Institutional Research and Development Program 95-LW-010; and Goddard Space Flight Center Director's Discretionary Fund. We are also grateful to Lawrence Berkeley Laboratory for assistance. This work was performed under the auspices of the U.S. Department of Energy by Lawrence Livermore National Laboratory under Contract W-7405-Eng-48.

\section{Reference}

Hurley, K., et al., Astron. Astrophys. Supp. Ser. 92(2), 401, 1995 


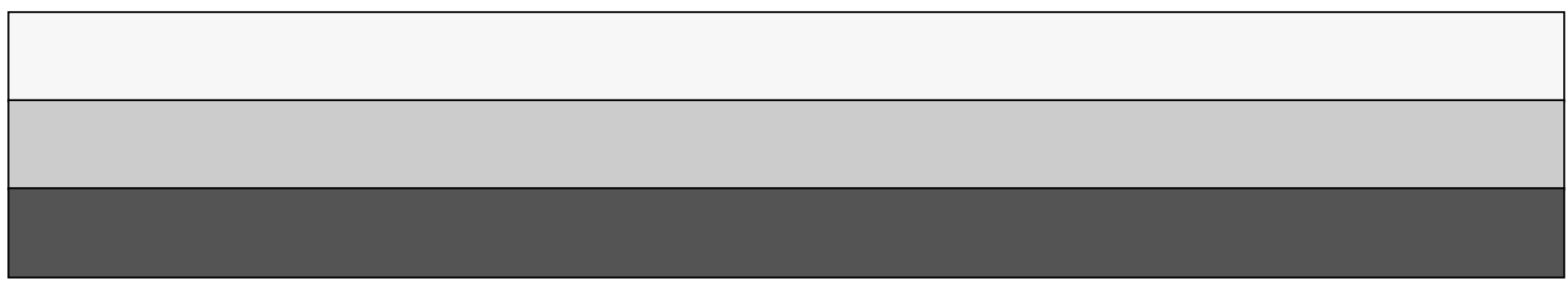

